did two other patients, a woman in the infirmary and a little girl in the children's ward. $\Lambda$ t this time within three days we had a total of thirteen cases develop: one, my assistant, one maid from the help's quarters, one from the men's side of the infirmary, two from the women's side of the infirmary, six from the girls' side of the children's pavilion and two from the women's cottages.

Ten days later there were two more from the wornen's cottage.

Three weeks after the first case develoned and about two weeks after the last of the first series, a three-year-old boy in the children's pavilion developed. He had been in close proximity to the girls first affected. $\Lambda$ t the same time the nurse in charge of the isolation developed symptoms. She had had scarlet fever once before, several years ago.

Threo weeks to the day after this and six weoks after the development of the first case, a case devoluped in one of the men's shacks.

It was at this time that we got you up. You isolated one boy from the children's pavilion whose throat culture proved negative and who never developed any symptoms. You isolated one whose throat culture was positive and who developed wellmarked scarlet fever. You isolated one whose throat you reported negative, but who next day had a wellmarked rash and typical symptoms. We had, therefore, at this second outbreak one man and the two boys from the children's pavilion.

On examining the patients, you isolated six suspects. In three of these the culture was positive. One of these had been in the Sanatorium since May 14th; a few days after admission had been laid up with a severe follicular tonsillitis. Ever since this time he had had a superficial ulcer at the margin of one of the tonsillar crypts and a slight persisting inflammation of the crypt. He had a tuberculous larynx. His throat was sprayed twice daily and the crypt had been treated from time to time. Two days after your first culture from his throat, I took a second culture, this time direct from the ulcer on the tonsil. This was positive. At the end of two weeks, after having the throat treated with 50\% argyrol, and after using trichloracetic acid a couple of times on the ulcer, we sent another culture to you. This culture was still positive, though that in the other isolated cases was now negative. At the end of three wecks we sent a fourth culture to you, which was negative. We had in the interim continued to trent the ulcer locally with trichlorncetic acid. With the isolation of this case and the two other suspects the epidemic stopped and we have had no further trouble.

Although this epidemic was studied only after some six months of observations on scarlet fever as described in my article on "The Control of Scarlet Fever," I felt secure enough of my grounds to try my procedures out where the usual routine of quarantine and fumigation had failed. With a physical examination of the tongue and throat of every individual on the premises, approximately 150 , I took throat cultures from all hyperemic throats, some thirty-five in number, and of this number had those isolated whom I believed might be carriers from the appearance of the tongue as well. Among the children I found two cases of the disease, isolating as well one boy with a possible scarlet fever throat. 'Two of the staff members numbered the culture slips and made for themselves a key record of these numbers and the names corresponding. The following day I gave them the record of the numbers which were checked on their list and in turn was given tha physical examination I had made the previous day. It will be seen that by the combination of examination and cultures, I had as exact knowledge as I have claimed possible in diphtheria. Cultures proved one of two fresh eases, disproved a possible fresh ease, proved three of six suspected carriers. On the strength of the cultures these other suspects with negative throats were freed from isolation.

Based on such evidence as the foregoing, I began the treatment of control of scarlet fever in exactly the same manner as I have described in a previous article, using the appearance of the streptococeus $S$ as a cause for search for either acute cases or carriers depending upon the field investigation. During the year and a half einployed, it has proved its value most exactly.

\section{CANCER OCCURRING IN ACID PARTS OF THE BODY.}

\author{
ISY A. I. Beneict, A.M., M.D., Buffalo,
}

Consultant in Digestive Discascs to Columbus Hospital; Attendant, Mcrcy Hospital; Editor "Buffalo Medical Journal."

Some years ago I published a statistic article showing the predominance of cancer in parts of the body having an acid secretion or especially liable to acid fermentation. It may be frankly admitted that this was prompted by the theory, somewhat in prominence at the time, that cancer was due to a yeast cell; but the statisties were given for what they were worth, without committing to the acceptance of this theory, and with due regard to the possibility that other conditions, such as mere mass of epithelium or special liability to mechanic and other irritating factors, aside from acidity, existed.

The latest large statistics available are those for the United States for 1914. They apply to the registration area and include malignant tumors in general, the error from the inclusion of sarcoma and the rarer malignant tumors, being small and probably self-neutralizing. Out of a total of 52,420 malignant tumors, the following may be tabulated:

Buccal cavity . ...........2,270

Stomach $\ldots \ldots \ldots \ldots \ldots \ldots \ldots . \ldots \ldots$ 12,768 
Rectum . . . . . . . . . . . 2,171

Uterus $\ldots \ldots \ldots \ldots \ldots \ldots \ldots \ldots, 7,470$

Vagina and vulva ............ 184

Kidneys and suprarenals ........ 538

Prostate ..................... 784

bladdor .................... 1,014

Jreast $\ldots \ldots \ldots \ldots \ldots \ldots \ldots \ldots, 5,423$

Skin $\ldots \ldots \ldots \ldots \ldots \ldots \ldots \ldots 1,957$

34,579

In the case of the uterus and breast, it is obvious that some cancers may be primary in parts not reached by the acid vaginal secretion and perspiration, or foci of fermontation at the nipple. Suprarenal tumors should be subtracted, but are sinall in number. On the other hand, we have 6,458 tumors of the liver and gall-bladder. Most authorities hold that the great majority of the former are secondary to those of the stomach, and the latter develop in gall-bladders more or less subject to bacterial involvement. Four thousand and fifty-one intestinal eancers are listed. As various critical statistics show that only about $10 \%$ of all intestinal cancers develop between the portion subject to irrigation by acid gastric juice and that subject to acid fermentation, it is obvious that this large number must include many belonging in the latter group-indeed, it is obvious at a glance that it is impossible that 2-3 of the total intestinal cancers should lie above the rectum. It is, if anything, an understatement to say that 3,000 of the liver and gall-bladder cancers and 3,000 of the unspecified intestimal cancors should be added to the above table, making the total above 40,000 , well above $75 \%$ and close to $80 \%$, involving epithelium more or less exposed to some form of acid reaction. Without attempting to promulgate a new theory, this fact is worth consideration, especially in the present uncertain state of our knowledge of the essential nature and cause of cancer.

\section{Nove $\mathfrak{I}$ natrumtrnt.}

\section{$\Lambda N$ IMPROVED VENIPUNCTURE NEEDLE.}

\section{Ry Guy G. Fernatd, M.D., Concond, Mass.}

Tine Journal of the American Medical Association, August 26, 1916, p. 1107, presented an illustrated description of the Brandeis needle for venipuneture. It will be found in practice that a slight modification of this needle is an improvement.

The needle consists of a straight steel tube 6 $\mathrm{cm}$. long, provided at about the middle of its length with a tab or flange of braized-on metal. When collecting sera this projecting flange is scized in a long-handled hemostat or in a needleholder or other selected lock-handle instrument which, together with the sterile and cotton-stoppered tube, is held firmly in the operator's hand. Ease and competence of grasp and certainty of direction for the necdle are insured by this means provided the metal flange of the needle is correctly corrugated to fit the corrugations of the needle-holder jaws. With this instrument the uncertainties of venipuncture are practically eliminated.

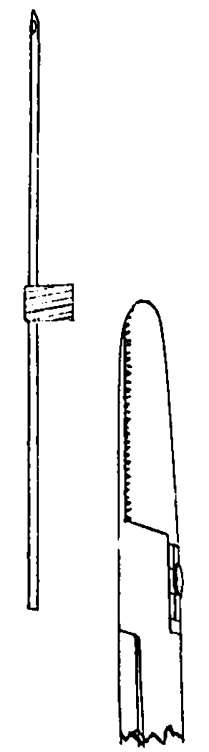

In operating for the administration of solution intravenously by gravity or other positive pressure methods the same happy results are secured by using a special needle-holder with the jaws adapted to hold securely the female coupling of one's favorite needle. 'The advantage of any straight needle over any curved device is obvious to experienced operators; the lumen of a curved needle cannot be kept clean and polished by vigorous use of the obturator, while that of the straight needle may be.

Incidentally these needles may be conveniently cleansed and sterilized between punctures by using the obturator consistently after each flushing-out with sterile water and alcohol alternately. Wash bottles with adapted nozzles will serve the purpose. Merely immersing a needle in a solution is much less likely to insure asepsis than is the vigorous flushing and polishing with obturator above indicated.

A simple expedient, by no means in general use, is the overfilling of the veins of the arm on which venipuncture is to be done by having the patient sit or lie and thrust one hand and one arm down vertically while the other is thrust upward in the same direction. When after a few seconds, the tourniquet is applied over the biceps of the dependent arm, the opcrator has availed himself of the action of a simple law of hydrostatics and has a well plumped-up vein to operate upon. 